\title{
Multiple wedge-shaped retinal nerve fiber layer defects in a patient with optic nerve glioma in the contralateral eye: case report
}

\author{
Múltiplos defeitos localizados da camada de fibras nervosas em um paciente \\ com glioma de nervo óptico no olho contralateral: relato de caso
}

Fernanda Pedreira Magalhães

Tiago Santos Prata ${ }^{2}$

Verônica Castro Lima ${ }^{3}$

Luiz Fernando Teixeira ${ }^{4}$

PauloGóis Manso ${ }^{5}$

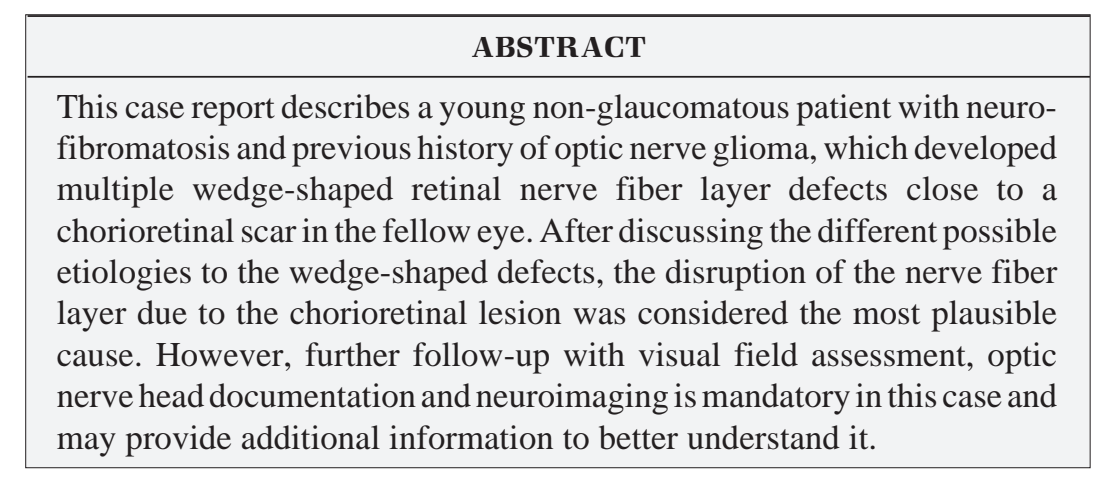

Keywords: Nerve fibers/abnormalities; Cicatrix; Retinal diseases; Optic nerve glioma; Case reports [Publication type]

\section{INTRODUCTION}

Retinal nerve fiber layer (RNFL) defect has been considered an important parameter for early diagnosis of glaucoma. It was first described by Hoyt as the earliest objective evidence of nerve fiber loss in eyes with chronically elevated intraocular pressure (IOP) ${ }^{(1)}$.

Although wedge-shaped RNFL defects are suggestive of glaucomatous optic neuropathy, they have been described in association with different ocular conditions, such as optic nerve drusen ${ }^{(2)}$, optic neuritis ${ }^{(3)}$, anterior ischemic optic neuropathy ${ }^{(4)}$, retinal cotton wool spots ${ }^{(5)}$, toxoplasmosis chorioretinal scars ${ }^{(6)}$, diabetic retinopathy ${ }^{(7)}$, and have been found in normal eyes as well ${ }^{(8)}$.

A case of a young non-glaucomatous patient presenting multiple wedge-shaped RNFL defects and a chorioretinal scar in his right eye, with a previous diagnosis of optic nerve glioma in the left eye is described.

\section{CASE REPORT}

An 18-year-old white man with a previous history of optic nerve glioma in his left eye, treated with chemotherapy four years ago, was referred to the glaucoma sector of the Federal University of São Paulo due to visual field loss in his right eye detected in a routine examination. He also presented type I neurofibromatosis and had been evaluated in the orbit sector. Throughout the entire glioma treatment, the patient did not receive any kind of steroid therapy. During ophthalmologic examination he pre- 
sented a best corrected visual acuity of 20/20 in his right eye and 20/30 in his left eye. Slit-lamp biomicroscopy was unremarkable. Gonioscopy disclosed a normal open angle and the IOP was $14 \mathrm{mmHg}$ in both eyes. Fundoscopy exam of the right eye revealed a normal and well defined optic nerve head $(\mathrm{ONH})$, with a physiological cup-to-disk ratio. Peripapillary gliosis could be observed in the inferior-nasal aspect of the nerve. Multiple inferior-temporal wedge-shaped defects were observed in the RNFL, one of them close to a small chorioretinal scar (Figure 1). The left eye presented a pale $\mathrm{ONH}$ and normal retina.

Concerning ancillary exams, the central corneal thickness was $554 \mu \mathrm{m}$ in the right eye and $544 \mu \mathrm{m}$ in the left eye. Visual field, accessed by standard automated perimetry (Humphrey Swedish Interactive Threshold Algorithm - Standard 24-2, Carl Zeiss Meditec, Dublin, CA), revealed a superior paracentral relative scotoma in the right eye (Figure $2 \mathrm{~A}$ ) and an inferior altitudinal defect in the left eye. Despite normal optic nerve head topographic results, the glaucoma probability score provided by the confocal scanning laser ophthalmoscopy (HRTIII, Heidelberg Retina Tomograph, Heidelberg Engineering $\mathrm{GmbH}$, Germany) was borderline in the right eye (Figure 2B). Nerve fiber layer analysis with scanning laser polarimetry (GDx VCC - Laser Diagnostic Technologies, San Diego, CA) showed inferior-temporal thinning in the right eye (Figure 2C) and diffuse loss in the left eye. Optical coherence tomography exam (Stratus OCT - Carl Zeiss Meditec, Dublin, CA; (Figure 2D) also revealed an inferior-temporal RNFL thinning in the right eye compatible with the other exams. Finally, the tumor evaluation by magnetic resonance imaging of the orbits demonstrated a lesion restricted to the left side not involving the optic chiasm (Figure 3).

\section{DISCUSSION}

At times, when pre-perimetric diagnosis of glaucoma is the goal, the search for subtle signs of damage in the RNFL is of utmost importance. The presence of RNFL defects in a patient without glaucoma is very unusual and it has been shown to be among the earliest signs of glaucomatous damage ${ }^{(8)}$. However, a young patient with normal IOP and physiological cup-to-disk ratio, as we have just described, is unlikely to have glaucoma.

Concerning the physiologic features of the RNFL, Jonas et al. ${ }^{(9)}$ have found that in normal eyes it is usually best visible in the inferior temporal region during the fundus examination, followed by the superior temporal region, the nasal superior region and the nasal inferior region. With increasing age, RNFL visibility decreases diffusely without giving preference to special fundus regions and without the development of localized defects. The fact that our case involves a young patient with RNFL defects localized in an inferior temporal region may have augmented the visibility of the defects.

In most of the optic nerve diseases, visibility of the RNFL is decreased, in addition to the age-related loss, in a diffuse and/or localized manner. The localized defects are wedgeshaped (not spindle-like defects), running towards or touching the optic disk border and typically occur in about $20 \%$ of all glaucomatous eyes ${ }^{(9)}$. These features strongly correlate with the RNFL findings of our patient, since he presents a diffuse loss in the eye affected by the glioma and wedge-shaped defects in the fellow eye. The possibility of an optic nerve glioma in the right eye causing the defects but no visual symptoms was also excluded by magnetic resonance imaging as previously described.
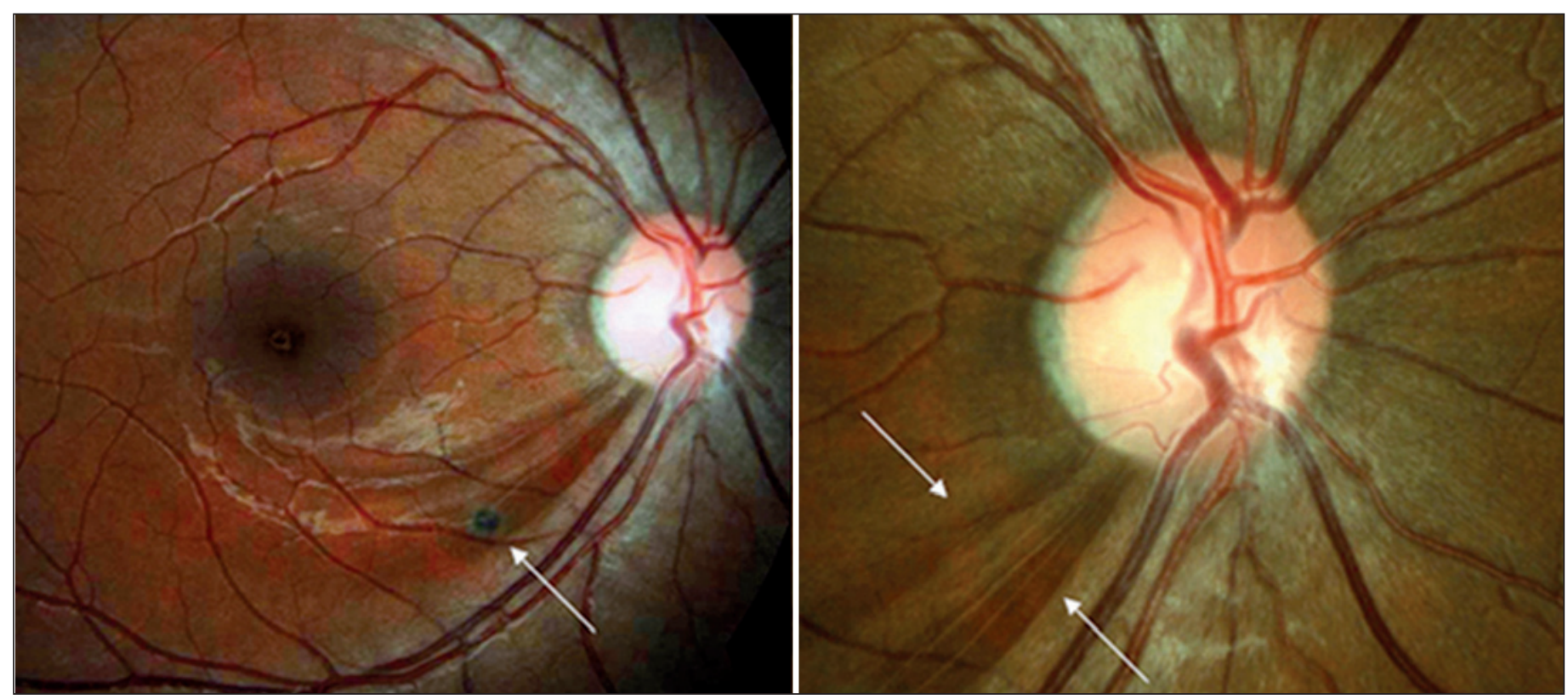

Figure 1 - Multiple inferior-temporal retinal nerve fiber layer defects (right arrow) close to a small chorioretinal scar (left arrow) in the right eye 


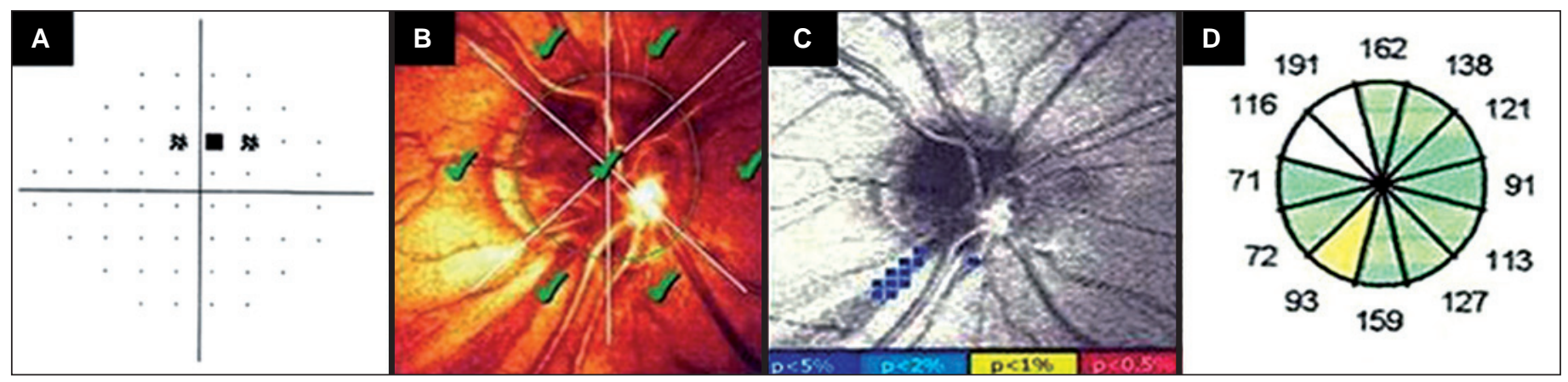

Figure 2 - A) Visual field of the same eye showing a superior defect; B) HRT-III showing a normal optic nerve head topographic analysis; C) GDX - VCC presenting a correspondent inferior retinal fiber layer defect; D) Stratus OCT retinal nerve fiber layer thickness map showing a correspondent inferior-temporal thinning
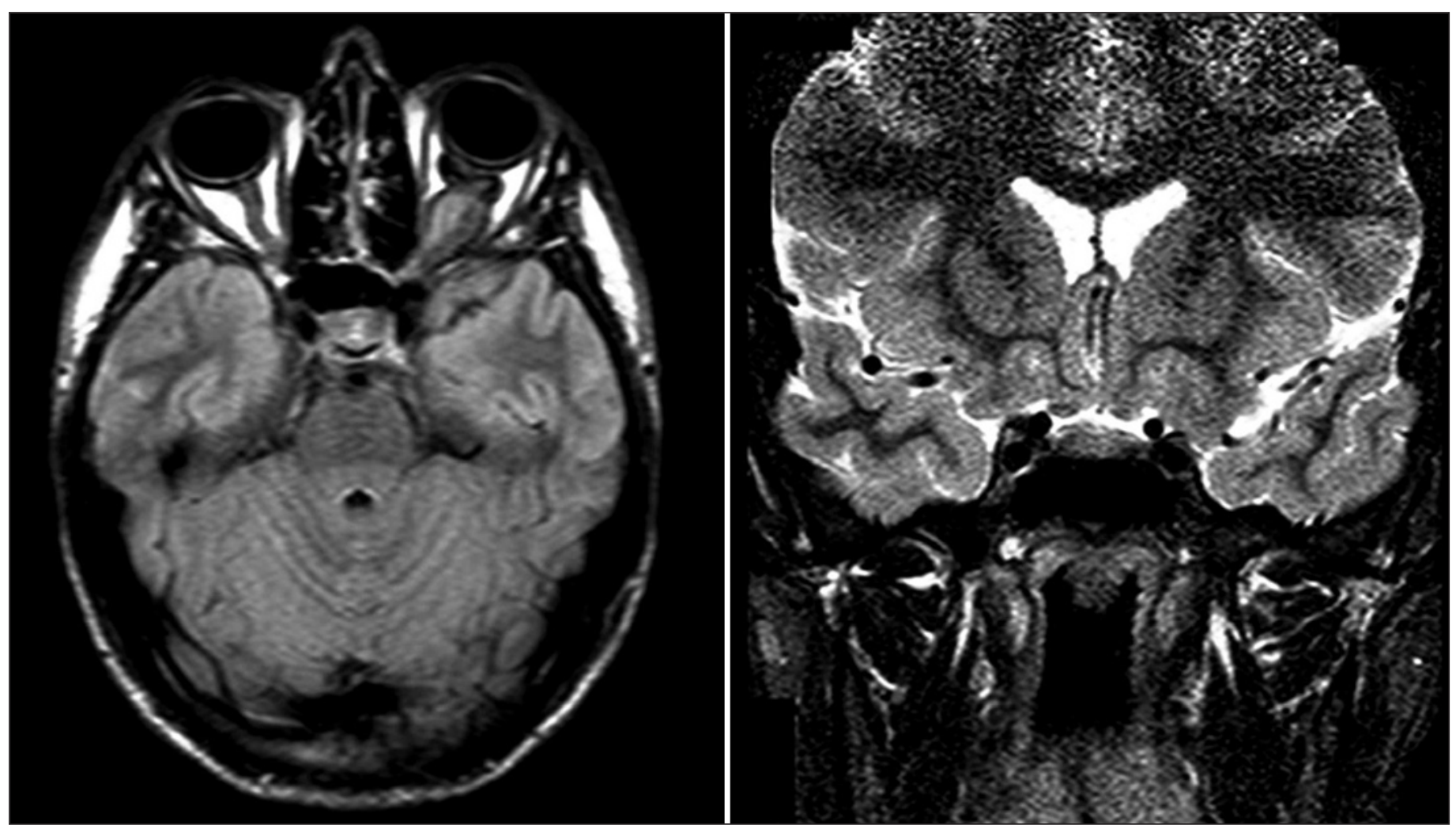

Figure 3 - A) MRI axial scan showing the glioma affecting the left optic nerve and absence of right optic nerve involvement; B) No signs of chiasmatic involvementin the MRI coronal scan

Some hypotheses could be made about the possible etiologies for this case. Sector scotomas associated with posterior uveitis such as toxoplasmosis have already been described. They could result from the disruption of the nerve fiber layer caused by chorioretinal lesions ${ }^{(6)}$. Even though in the actual fundus exam our patient presented one small chorioretinal scar, the peripapillary gliosis could be a result of more extensive inflammation, but there is no possibility to know the magnitude and extension of the previous inflammatory process.

Optic nerve glioma could be another possible explanation for a non-glaucomatous RNFL defect. A tumor that involves the optic chiasm could lead to nerve fiber loss in the fellow eye. More specifically, crossing nasal fibers would be the first affected resulting in a temporal scotoma that would respect the vertical median line. Also, patients with neurofibromatosis can have bilateral optic nerve gliomas ${ }^{(10)}$. They can be diffuse and the total extension can be difficult to determine in the imaging exams. In our case, evaluation with magnetic resonance imaging showed that the tumor did not reach the optic chiasm or the fellow eye. Also our patient did not present a suggestive visual field defect for this condition. Although we believe that optic nerve glioma affecting the right eye is a 
very unlikely etiology for the localized RNFL defects in our patient, we cannot completely exclude this possibility due to these specific characteristics previously described.

There are several ocular and systemic conditions that have been described associated to RNFL defects, such as optic nerve head drusen, optic neuritis, non ischemic optic neuropathy and retinal cotton-wool spots ${ }^{(2-5)}$. However, most of them do not apply to this case. Since our patient did not receive any kind of steroid therapy, steroid induced damage is very unlikely to have occurred. Although RNFL defects have been observed after optic disc hemorrhages in normal-tension glaucoma cases ${ }^{(11)}$, our patient was young with no signs of glaucomatous optic neuropathy, and thus unlikely to have this condition. Alencar et al. ${ }^{(8)}$ have described a similar case presenting a RNFL defect associated with visual field loss in a normal patient with a healthy neuroretinal rim. This idiopathic RNFL defect should also be considered as a possible explanation for the present case.

This case report describes a young patient with neurofibromatosis, with multiple RNFL defects close to a small chorioretinal scar in his right eye and a treated optic nerve glioma in the fellow eye. To the best of our knowledge, there is no similar previous report that could help identifying the real explanation for these findings. A further follow-up with clinical examination, visual field assessment, optic nerve documentation and neuroimaging is crucial and may provide additional information to better understand this case.

\section{ACKNOWLEDGMENTS}

We would like to thank Dr. Deise Mitsuko Nakanami for the contribution in the management and follow up of this patient.

\section{RESUMO}

Este relato de caso descreve um paciente jovem, sem diagnóstico de glaucoma, portador de neurofibromatose e com história prévia de glioma de nervo óptico em um olho, que desenvolveu múltiplos defeitos localizados na camada de fibras nervosas próximos a uma cicatriz coriorretiniana no olho contralateral. Depois de discutir as diferentes etiologias possíveis para os defeitos localizados, a desorganização da camada de fibras nervosas secundária à lesão coriorretiniana foi considerada a causa mais plausível. Contudo, futuro acompanhamento com campo visual, documentação da cabeça do nervo óptico e neuroimagem é mandatório neste caso e pode fornecer informações adicionais para melhor entendê-lo.

Descritores: Fibras nervosas/anormalidades; Cicatriz; Doenças da retina; Glioma de nervo óptico; Relatos de casos [Tipo de publicação]

\section{REFERENCES}

1. Hoyt WF, Frisén L, Newman NM. Fundoscopy of nerve fiber layer defects in glaucoma. Invest Ophthalmol. 1973;12(11):814-29.

2. Katz BJ, Pomeranz HD. Visual field defects and retinal nerve fiber layer defects in eyes with buried optic nerve drusen. Am J Ophthalmol. 2006;141(2):248-53.

3. Zaveri MS, Conger A, Salter A, Frohman TC, Galetta SL, Markowitz CE, et al. Retinal imaging by laser polarimetry and optical coherence tomography evidence of axonal degeneration in multiple sclerosis. Arch Neurol. 2008; 65(7):924-8.

4. Danesh-Meyer HV, Carroll SC, Ku JY, Hsiang J, Gaskin B, Gamble GG, Savino PJ. Correlation of retinal nerve fiber layer measured by scanning laser polarimeter to visual field in ischemic optic neuropathy. Arch Ophthalmol. 2006;124(12):1720-6.

5. Alencar LM, Medeiros FA, Weinreb R. Progressive localized retinal nerve fiber layer loss following a retinal cotton wool spot. Semin Ophthalmol. 2007; 22(2):103-4.

6. Martin WG, Brown GC, Parrish RK, Kimball R, Naidoff MA, Benson WE. Ocular toxoplasmosis and visual field defects. Am J Ophthalmol. 1980;90(1):25-9.

7. Chihara E, Matsuoka T, Ogura Y, Matsumura M. Retinal nerve fiber layer defect as an early manifestation of diabetic retinopathy. Ophthalmology. 1993; 100(8):1147-51.

8. Alencar LP, Konno F, Raiza AC, Susanna R Jr. Retinal nerve fiber layer defect in a patient with healthy neuroretinal rim. Clinics (Sao Paulo). 2007;62(2):197-8.

9. Jonas JB, Dichtl A. Evaluation of the retinal nerve fiber layer. Surv Ophthalmol. 1996;40(5):369-78.

10. Thiagalingam S, Flaherty M, Billson F, North K. Neurofibromatosis type 1 and optic pathway gliomas: follow-up of 54 patients. Ophthalmology. 2004;111(3): 568-77.

11. Sugiyama K, Tomita G, Kitazawa Y, Onda E, Shinohara H, Park KH. The associations of optic disc hemorrhage with retinal nerve fiber layer defect and peripapillary atrophy in normal-tension glaucoma. Ophthalmology. 1997; 104(11):1926-33. 